\title{
Türk Bankacılık Sektöründe Maliyet Etkinliği (2005-2013)
}

\author{
Cost Efficiency In Turkish Banking Sector (2005-2013)
}

A. Elif AY YALÇINKAYA' ${ }^{1}$, Recep KÖK²

\begin{abstract}
ÖZET
Türkiye ekonomisi açısından bağımsız karar alma birimi olan bankalar özelinde kredi mekanizmasının nasıl işlediği, bankalar arasında kaynak tahsisinin hangi ölçüde başarıldığı konusu, bu araştırmanın temel motivasyonunu oluşturmaktadır. Bu çalışmada 2005 - 2013 yılları arasında Türkiye'de faaliyet gösteren 21 bankanın veri tabanından yararlanılarak parametrik yöntemlerden stokastik sınır analizi (SFA) kullanılmaktadır. Aynı koşullarda faaliyet gösteren ve aynı çıktıyı üreten en etkin bankayla karşılaştırmalı olarak, diğer bankaların ağırlıklı ortalama maliyet etkinliği hesaplanmıştır. Elde edilen etkinsizliğin etkileri analizine göre analiz döneminde kredi maliyetlerinde ortaya çıkan belirgin artışların, finans sistemi üzerinde kaynak tahsisini bozucu etkisi belirlenmiştir. Bu bağlamda maliyet etkinsizliğine yol açan içsel ve dışsal nedensellikler tartışılarak politika önermeleri geliştirilmiştir.
\end{abstract}

Anahtar Kelimeler: Banka, Maliyet Etkinliği, Stokastik Sınır Analizi, Etkinsizliğin Etkileri

\section{Giriş}

Küresel ekonomik bağlantıların özellikle finans sektörleri üzerinden gecikmesiz sinyaller vermiş olması ve sektörün bu sinyallere daha duyarlı tepki göstermesi bankacılık endüstrisinin (algıyı güçlendirmek için çalışmada endüstri yerine sektör kavramı kullanılmıştır) araştırma konusu olarak seçilmesinde birincil etkendir. Nitekim sektör 2008'den beri yaşanan küresel bunalımın etkisi altındadır ve bu etki halen önemini korumaktadır. Türkiye Bankalar Birliği'ne göre; 2008-2013 döneminde, küresel piyasalarda yaşanan yuiksek risk ve belirsizlik ortamında Türkiye ekonomisi finansal istikrara yönelik güçlü bir görünüm sergilemiştir. Finansal sektörün çok büyuik bir bolümünü oluşturan

\begin{abstract}
This study examines how credit mechanism works in banking and whether resource allocation between the banks is efficient or not. We use stochastic frontier analysis (SFA) that is one of the parametric methods, by using the database for 21 banks in Turkey for the period of 2005-2013. The weighted average cost efficiency of the banks is measured in comparison with the most efficient bank that performs under the same conditions and that produces the same output with them. According to the analytical findings, we determine that increasing of credit cost affects resource allocation disruptively in financial system. As regards, some suggestions are developed on economic policy via internal and external causilities that bring about cost inefficiency.
\end{abstract}

Keywords: Banks, Cost Efficiency, Stochastic Frontier Analysis, Effects of Inefficiency 
sermaye ve ölçek yapılarına göre alt gruplarının durumu analiz edilmiştir. Bu temelde, Türkiye'deki mevduat bankalarının maliyet etkin çalışıp çalışmadıklarının belirlenmesi amaçlanmıştır.

$\mathrm{Bu}$ amaç çerçevesinde, öncelikle analize konu olan veri seti, değişken tanımlamalar ve tanı istatistiklerinin ardından model ve analitik bulgulara yer verilmektedir.

\section{MALIYYT ETKINLIĞi ANALizi}

Maliyet etkinliğine ilişkin olarak yazında çok sayıda çalışmaya rastlamak mümkündür. Bu çalışma kapsamında, yazın taramasında, bankacılık sektörüne yönelik maliyet etkinliği çalışmalarına kısaca yer verilmektedir.

Işık ve Hassan (2002)'ın çalışmasında, 19881996 döneminde Türk bankacılık sektörüne ilişkin maliyet ve kar etkinlikleri değerlendirilmektedir. Bu çalışmada Işık ve Hassan, etkinlik üzerinde, banka ölçeği, yönetimi ve mülkiyet yapısı gibi değişkenlerin etkisini ele almaktadırlar. İşgücü fiyatı, sermaye fiyatı ve mevduat ve mevduat dışı varlıklara ödenen faiz olarak fon fiyatları şeklinde üç girdi ve kısa vadeli ticari krediler, uzun vadeli ticari krediler, teminat mektubu, repo ve döviz işlemleri gibi riske göre ayarlanmış bilanço dışı varlıklar ve menkul kıymetler, interbank fonları gibi diğer varlıklar şeklinde dört çıktı kullanılmaktadır.

Kasman (2002)'ın çalışmasında, 1988-1998 dönemi Türk bankacılık sisteminde maliyet etkinliği, ölçek ekonomileri ve teknolojik ilerlemeyi araştırmak üzere; işgücü fiyatı, fiziki sermaye fiyatı ve fon fiyatları şeklinde üç girdili ve kısa vadeli krediler, uzun vadeli krediler ve menkul kıymetler şeklinde üç çıktılı stokastik sınır yaklaşımı kullanılarak hesaplanmıştır.

Günalp ve Çelik (2004), 1990-2000 dönemi için Türk bankalarında etkinliği kullanarak piyasa yapısı ve performans arasındaki ilişkiye dair hipotezleri test etmişlerdir.Çalışmada aracılıkyaklaşımı benimsenerek toplam maliyetler işletme ve faiz giderlerinin toplamı; çıktı değişkeni toplam krediler; girdiler ise işgücünün fiyatı, sermayenin fiyatı ve mevduatın fiyatı olarak belirlenmiştir.

El-Gamal ve İnanoğlu (2005), 1990-2000 yılları arasında Türkiye'de faaliyet gösteren 49 bankanın maliyet etkinliğini stokastik sınır yaklaşımı ile hesaplamışlardır. Modelde çıktı olarak kredi hacmi, girdi olarak işgücü fiyatı, fiziki sermaye fiyatı ve fon fiyatı alınmıştır. Ayrıca kalite endeksi (donuk krediler/ toplam krediler) ve risk endeksi (özkaynaklar/toplam varlıklar) modele dahil edilmiştir.

Dikmen (2013), ekonomik kriz gibi şokların olmadığı 2003-2007 dönemine ilişkin olarak Türkiye'de faaliyet gösteren 32 ticari bankaya ait panel verilerle stokastik translog maliyet ve kar denklemleri tahmin etmiştir. Toplam krediler ve menkul değerler çıktı; işgücü, sermaye ve mevduat fiyatı ise girdi olarak kullanılmıştır.

Yazında bankacılık sektörünün maliyet etkinliğinin hesaplanmasına ilişkin çalışmalar değerlendirildiğinde girdi ve çıtı değişkenleri genellikle benzerlik gösterirken; etkinsizliğin etkilerinin de ele alındığı çalışmalarda ise farklı değişkenler kullanılmaktadır. Bu kısımda yazın çerçevesinde analize konu olan veri setine, değişken tanımlamalarına ve tanı istatistiklerinin yanı sıra model ve analitik bulgulara yer verilmektedir.

\subsection{Veri Seti, Değişken Tanımlamalar ve Tanı İstatistikleri}

\subsubsection{Veri Seti}

Bu çalışmada, karar alma birimlerinin homojen olması ve benzer şartlar altında faaliyet göstermesi ölçütüne özen gösterildiği için kalkınma ve yatırım bankaları ile katılım bankaları (mevduat kabul etmediklerinden dolayı) modele dahil edilmemiş, bu kapsamda yalnızca mevduat bankaları (ticari bankalar) analiz konusu olarak seçilmiştir. Çalışma bağlamında, yabancı sermayeli mevduat bankalarından şube bankacılığı niteliğindeki "Türkiye'de şube açan yabancı sermayeli bankalar", sistem içinde belirleyici yönünün olmaması ve dahil edildiğinde sapmalı sonuçlar doğurması nedeniyle analiz kapsamından çıkarılmıştır. Ayrıca tasarruf mevduatı sigorta fonuna devredilen Birleşik Fon Bankası A.Ş. ve Adabank A.Ş., maliyet minimizasyonu amacıyla faaliyette bulunmadığı için modele dahil edilmemiştir. Yine Odea Bank A.Ş. ve Bank of Tokyo-Mitsubishi UFJTurkey A.Ş. sırasıyla 28 Eylül 2012 ve 19 Eylül 2013 tarihlerinde faaliyet izni aldığı ve bu çalışmanın dayandığı dönem olan 2005-2013 dönem aralığına uygun olmadığı için veri setine dahil edilmemiştir. Deutsche Bank A.Ş. ve Şekerbank T.A.Ş. ise sektör paylarının küçük olması ve verilerinde yüksek düzeyde sapmalı değerler içermesinden dolayı veri setinden çıkarılmıştır. $\mathrm{Bu}$ doğrultuda örneklemimiz 21 bankadan oluşmaktadır.

Türkiye'de 2005-2013 döneminde mevduat bankaları, bankacılık sisteminin \%96,3'ünü, kalkınma 
ve yatırım bankaları ise $\% 3,65^{\prime}$ ini oluşturmaktadır. Örneklemimizde yer alan 21 banka ise, toplam aktif büyüklüğü cinsinden 2005-2013 dönemindeki mevduat bankalarının \%96,8'ini, Türk bankacılık sisteminin ise \%93,3'ünü kapsamaktadır. Dolayısıyla yukarıda belirtildiği gibi inmal edilen karar alma birimleri analiz sonuçlarını etkilemeyecek kadar küçüktür. Bu kapsamda örneklemimizdeki bankaların listesi ile ölçek ve sermaye yapıları Tablo 1'den izlenebilmektedir.

Tablo 1: Sermaye ve Ölçek Yapısı Bakımından Örneklemdeki Bankalar

\begin{tabular}{|c|c|c|}
\hline Banka & Sermaye Yapısı & Ölçek Yapısı \\
\hline T.C. Ziraat Bankası A.Ş. & Kamusal sermayeli banka & Büyük ölçekli \\
\hline Türkiye Halk Bankası A.Ş. & Kamusal sermayeli banka & Büyük ölçekli \\
\hline Türkiye Vakıflar Bankası T.A.O. & Kamusal sermayeli banka & Büyük ölçekli \\
\hline Akbank T.A.Ş. & Özel sermayeli banka & Büyük ölçekli \\
\hline Anadolubank A.Ş. & Özel sermayeli banka & Küçük ölçekli \\
\hline $\begin{array}{l}\text { Fibabanka A.Ş. (Bank Europa } \\
\text { Bankası A.Ş. / Millenium Bank A.Ş.) }\end{array}$ & $\begin{array}{l}\text { Türkiye'de kurulmuş yabancı sermayeli banka (2005-2012) ve } \\
\text { özel sermayeli banka (2013) }\end{array}$ & Küçük ölçekli \\
\hline Tekstil Bankası A.Ş. & Özel sermayeli banka & Küçük ölçekli \\
\hline Turkish Bank A.Ş. & Özel sermayeli banka & Küçük ölçekli \\
\hline Türk Ekonomi Bankası A.Ş. & Özel sermayeli banka & Orta ölçekli \\
\hline Türkiye Garanti Bankası A.Ş. & Özel sermayeli banka & Büyük ölçekli \\
\hline Türkiye İş Bankası A.Ş. & Özel sermayeli banka & Büyük ölçekli \\
\hline Yapı ve Kredi Bankası A.Ş. & Özel sermayeli banka & Büyük ölçekli \\
\hline Alternatifbank A.Ş. & $\begin{array}{l}\text { Çalışmanın örneklem döneminin son 4,5 ayının öncesinde özel } \\
\text { sermayeli mevduat bankası statüsünde yer alan Banka, örneklem } \\
\text { döneminin son 4,5 ayı içinde ise Türkiye'de kurulmuş yabancı } \\
\text { sermeyeli banka statüsüne geçmiştir. Ancak bu durum sermaye } \\
\text { yapısına göre bankalar sınıflandırılırken dönemin çoğunluğu } \\
\text { dikkate alınarak değerlendirilmiş ve Alternatifbank A.Ş. özel } \\
\text { sermayeli mevduat bankası grubuna dahil edilmiştir. }\end{array}$ & Küçük ölçekli \\
\hline Arap Türk Bankası A.Ş. & Türkiye'de kurulmuş yabancı sermayeli banka & Küçük ölçekli \\
\hline $\begin{array}{l}\text { Burgan Bank A.Ş. (Tekfenbank A.Ş. } \\
\text { ve Eurobank Tekfen A.Ş.) }\end{array}$ & $\begin{array}{l}\text { Özel sermayeli banka (2006-2005) ve Türkiye'de kurulmuş } \\
\text { yabancı sermayeli banka (2013-2007) }\end{array}$ & Küçük ölçekli \\
\hline Citibank A.Ş. & Türkiye'de kurulmuş yabancı sermayeli banka & Küçük ölçekli \\
\hline Denizbank A.Ş. & $\begin{array}{l}\text { Özel sermayeli banka (2006-2005) ve Türkiye'de kurulmuş } \\
\text { yabancı sermayeli banka (2013-2007) }\end{array}$ & Orta ölçekli \\
\hline Finans Bank A.Ş. & $\begin{array}{l}\text { Özel sermayeli banka (2006-2005) ve Türkiye'de kurulmuş } \\
\text { yabancı sermayeli banka (2013-2007) }\end{array}$ & Orta ölçekli \\
\hline HSBC Bank A.Ş. & Türkiye'de kurulmuş yabancı sermayeli banka & Orta ölçekli \\
\hline ING Bank A.Ş. (Oyak Bank A.Ş.) & $\begin{array}{l}\text { Özel sermayeli banka (2007-2005) ve Türkiye'de kurulmuş } \\
\text { yabancı sermayeli banka (2013-2008) }\end{array}$ & Orta ölçekli \\
\hline Turkland Bank A.Ş. (MNG Bank A.Ş.) & $\begin{array}{l}\text { Özel sermayeli banka (2006-2005) ve Türkiye'de kurulmuş } \\
\text { yabancı sermayeli banka (2013-2007) }\end{array}$ & Küçük ölçekli \\
\hline
\end{tabular}

Kaynak: (1) Bankacılık Düzenleme ve Denetleme Kurumu, "Bankacılıkta Yapısal Gelişmeler: 2006-2011", http://www.bddk.org.tr/ WebSitesi/turkce/Raporlar/Bankacilikta_Yapisal_Gelismeler/Bankacilikta_Yapisal_Gelismeler.aspx, (06.05.2014).

(2) Türkiye Bankalar Birliği, “31.12.2013 Tarihi Itibariyle Üye Bankaların Bilgileri”, http://www.tbb.org.tr/modules/banka-bilgileri/banka_ Listesi.asp?tarih=31/12/2013, (06.05.2014).

Çalışmanın örneklemindeki 21 banka, BDDK'nın ölçütleri esas alınarak aktif büyüklüklerine göre ölçeklendirildiğinde; sektör toplamı içindeki payı \%5'in üzerinde olan bankalar büyük, \%1-\%5 arasında olanlar orta, \%1'in altında olan bankalar küçük ölçekli banka olarak sınıflandırımıştır. Bu kapsamda, Türkiye Bankalar Birliği'nin Veri Sorgulama Sistemi'nden elde edilen bankaların aktif büyüklükleri verisi incelendiğinde 7 bankadan oluşan büyük ölçekli bankalar grubunun sektördeki payı \%82,6 olarak gerçekleşirken; 5 bankanın bulunduğu orta ölçekli bankalar grubunun payı \%14,9; küçük ölçekli bankalar grubunun payı ise \%3,3'tür. Büyük ölçekli bankaların piyasa payı 2005 yılında \% 84,8 iken 2013 yılında \% 80,4 'tür. Orta ölçekli bankaların piyasa payı ise 2005 
- 2013 döneminde \%12,2'den \%16,3'e, küçük ölçekli bankaların payı ise $\% 3$ 'ten, \%3,3'e yükselmiştir.

Bankaların sermaye yapılarına göre piyasa payları ise şu şekilde özetlenebilmektedir: En büyük paya özel sermayeli mevduat bankaları $(\% 56,8)$ sahipken, sırasıyla kamusal sermayeli $(\% 32,2)$ ve yabancı sermayeli mevduat bankaları $(\% 10,9)$ takip etmektedir. 2005 - 2013 döneminde özel sermayeli mevduat bankalarının piyasa payı $\% 61,7$ 'den $\% 54,1$ 'e ve kamusal sermayeli mevduat bankalarının piyasa payı da \%35,1'den \%31,7'ye gerilerken, yabancı sermayeli mevduat bankalarının piyasa payı ise \%3,2'den \%14,2'ye yükselmiştir. Örnekleme ilişkin kapsamın ve veri setinin belirlenmesinin ardından, modele temel oluşturacak değişken tanımlamalarına ve tanı istatistiklerine yer verilmektedir.

\subsubsection{Değişken Tanımlamaları ve Tanı istatistikleri}

Hizmet sektörünün çıktıları firmalar için dışsaldır (talep yönlü) ve depolanamamaktadır. Bu nedenle bankalara yönelik çalışmalarda maliyet fonksiyonu, üretim fonksiyonuna göre daha sık kullanılmakta ve daha uygun bir yaklaşım olarak benimsenmektedir. (Wang ve Kumbhakar, 2009: 36) Ayrıca maliyet fonksiyonunun, üretim fonksiyonuna göre başka bir üstünlüğü ise birden fazla çıkının ele alınabilmesidir. (Kumbhakar ve Lovell, 2003: 51) Bu kapsamda, çalışmada bankaların etkinliğinin hesaplanmasında maliyet fonksiyonu kullanılmıştır. Çalışmamızda bağımlı değişken olarak, faiz giderlerinin ve faiz dışı giderlerin (diğer faaliyet giderlerinin) toplamı olan toplam giderler alınmıştır. Bağımsız değişkenler iki gruba ayrılarak ele alınmıştır: Sınır değişkenleri ve etkinsizlik etkileridir. Sınır değişkenleri kapsamında, çalışmada maliyet fonksiyonu kullanıldığı için çıktı miktarı ve girdi fiyatları belirlenmiştir. Ancak çıkıların finansal kesimde soyut olmasından dolayı belirlenmesinde zorluk yaşanmaktadır. En tartışmalı konu ise mevduatların rolüdür. (Resti, 1997: 221-225) Yazında temel olaraküç farklı yaklaşım bulunmaktadır: Varlık (asset) veya aracılık (intermediation) yaklaşımı, kullanıcı maliyeti (user cost) yaklaşımı ve katma değer (value added) yaklaşımı şeklindedir.

Aracılık veya varlık yaklaşımında, mevduatlar, üretim sürecinde bir girdi iken, katma değer ve kullanıcı maliyeti yaklaşımında mevduatlar çıktı olarak alınmaktadır. Sealy ve Lindley (1977) tarafından ortaya konan aracılık yaklaşımında ise bankalar sermaye, emek ve mevduatları kullanarak kredi ve diğer gelir getiren varlıkları üreten ve tasarruf sahipleriyle yatırımcılar arasında finansal kaynakların transferini gerçekleştiren finansal aracılar olarak ele alınmaktadır. Hancock (1985) tarafından ortaya konan kullanıcı maliyeti yaklaşımında, bankanın gelirine katkısı bakımından değerlendirilerek bankacılık aktiviteleri girdi veya çıktı olarak ele alınmıştır. Berger ve Humprey (1992) tarafından ortaya konan katma değer yaklaşımında ise bankalar hem finansal aracılar hem de mevduat tutma gibi finansal hizmetleri sağlayan kuruluşlar olarak görüldüğü için mevduatlar hem girdi hem de çıktı olarak ele alınmıştır.

Berger ve Humphrey (1997), mükemmel bir yaklaşımın bulunmadığını, ancak katma değer yaklaşımının finansal kurumların şubelerinin etkinliğinin ölçümünde, aracılık yaklaşımının ise toplam maliyetlerin içinde büyük bir bölümünü oluşturan faiz giderlerinin de dikkate alınması nedeniyle finansal kurumları bütünüyle değerlendirirken daha uygun olacağını vurgulamışlardır. Bu çalışmada bankalar arası karşılaştırma yapılmasından dolayı aracılık yaklaşımı kullanılmıştır. Aracılık yaklaşımı çerçevesinde, finansal sektörün maliyet etkinliği analizinde kullanılan değişkenlerin tanımlamaları Tablo 2'de gösterilmiştir: 
Tablo 2: Değişken Tanımlamaları

\begin{tabular}{|c|c|}
\hline Değişken & Değişken Adı \\
\hline \multicolumn{2}{|r|}{ BAĞIMLI DEĞIŞKEN } \\
\hline $\mathrm{TC}$ & Toplam giderler (Faiz giderleri ve faiz dışı giderler) \\
\hline \multicolumn{2}{|r|}{ ÇIKTI MIKTARLARI } \\
\hline$y_{1}$ & Krediler ve alacaklar (Kısa, orta ve uzun vadeli krediler) \\
\hline $\mathbf{y}_{2}$ & $\begin{array}{l}\text { Diğer gelir getiren varlıklar (Finansal varlıklar, para piyasalarından alacaklar, satılmaya hazır finansal var- } \\
\text { lıklar, vadeye kadar tutulacak yatırımlar) }\end{array}$ \\
\hline \multicolumn{2}{|r|}{ GIRDi FIYATLARI } \\
\hline $\mathbf{p}_{1}$ & Mevduat (Borçlanma) fiyatı (Mevduata ödenen faiz gideri / Toplam mevduat) \\
\hline $\mathbf{p}_{2}$ & Emek fiyatı (Personel giderleri / Personel sayısı) \\
\hline $\mathbf{p}_{3}$ & Sermaye fiyatı (Amortisman giderleri / Maddi duran varlıklar) \\
\hline $\mathbf{q}$ & Özkaynaklar \\
\hline $\mathbf{T}$ & Trend \\
\hline \multicolumn{2}{|r|}{ ETKINSIZLiĞîN ETKILERi } \\
\hline d1 & Mevduatın krediye dönüştürülme oranı (Krediler ve alacaklar / Mevduat) \\
\hline d2 & Kredi kayıp karşılığı \\
\hline d3 & Likidite oranı (Nakit değerler ve Merkez Bankası / Toplam aktifler) \\
\hline d4 & Toplam krediler ve alacaklar / Toplam aktifler \\
\hline d5 & Personel giderleri / Diğer faaliyet giderleri \\
\hline d6 & Faiz karşılama oranı (Faiz gelirleri / Faiz giderleri) \\
\hline
\end{tabular}

Değişkenlere ilişkin veri tabanı oluşturulurken Türkiye Bankalar Birliği Veri Sorgulama Sistemi'nde yer alan Mali Tablolardan yararlanılmıştır. Değişkenlerde kullanılan ham verilerin birimi sistemde yer aldığı şekliyle 1000 TL olarak düzenlenmiştir. Maliyet etkinliği hesaplanmasında bankalar sermaye ve ölçek yapıları bazında alt gruplar şeklinde analiz edildiği için modelde yer alan değişkenlere ilişkin tanımlayıcı istatistikler de alt gruplar bazında Tablo 3 'te verilmektedir. 
Tablo 3: Tanımlayıcı İstatistikler

\begin{tabular}{|c|c|c|c|c|c|c|c|}
\hline & $\begin{array}{l}\text { Mevduat } \\
\text { Bankaları }\end{array}$ & $\begin{array}{r}\text { Kamusal } \\
\text { Sermayeli } \\
\text { Bankalar }\end{array}$ & $\begin{array}{r}\text { Özel } \\
\text { Sermayeli } \\
\text { Bankaları }\end{array}$ & $\begin{array}{r}\text { Türkiye'de } \\
\text { Kurulmuş Yab. } \\
\text { Ser. Bankalar }\end{array}$ & $\begin{array}{r}\text { Büyüuk } \\
\text { Ölçekli } \\
\text { Bankalar }\end{array}$ & $\begin{array}{r}\text { Orta Ölçekli } \\
\text { Bankalar }\end{array}$ & $\begin{array}{r}\text { Küçüuk } \\
\text { Ölçekli } \\
\text { Bankalar }\end{array}$ \\
\hline \multirow{2}{*}{ TC } & 3.448 .245 & 7.428 .498 & 3.854 .026 & 1.343 .832 & 8.195 .992 & 2.469 .422 & 299.343 \\
\hline & (3.836.735) & $(2.728 .964)$ & $(4.268 .110)$ & (1.481.565) & $(2.619 .845)$ & $(1.272 .320)$ & $(232.544)$ \\
\hline \multirow[b]{2}{*}{$y_{1}$} & 21.381 .607 & 2.681 .217 & 24.856 .265 & 8.363 .743 & 50.723 .516 & 15.754 .015 & 1.686 .563 \\
\hline & (28.185.063) & (27.311.779) & (32.581.396) & (10.307.829) & (30.474.010) & (10.145.193) & (1.398.735) \\
\hline \multirow[b]{2}{*}{$y_{2}$} & 11.470 .994 & 32.512 .736 & 11.910 .767 & 2.644 .530 & 30.437 .883 & 4.299 .495 & 703.135 \\
\hline & $(16.610 .274)$ & $(21.232 .078)$ & $(15.531 .297)$ & (2.990.993) & $(16.593 .880)$ & $(2.925 .491)$ & (797.393) \\
\hline \multirow{2}{*}{$\mathbf{p}_{1}$} & 0,06635 & 0,07772 & 0,06905 & 0,05827 & 0,07096 & 0,06766 & 0,06205 \\
\hline & $(0,02421)$ & $(0,02850)$ & $(0,02028)$ & $(0,02503)$ & $(0,02429)$ & $(0,01950)$ & $(0,02598)$ \\
\hline \multirow[b]{2}{*}{$\mathbf{p}_{2}$} & 62,52791 & 52,02853 & 57,45966 & 73,46747 & 58,08396 & 56,22499 & 69,48593 \\
\hline & $(20,36354)$ & $(12,33823)$ & $(16,37566)$ & $(22,91509)$ & $(14,82397)$ & $(14,31150)$ & $(24,58880)$ \\
\hline \multirow[b]{2}{*}{$\mathbf{p}_{3}$} & & & 0,16637 & & & & 0,20867 \\
\hline & $(0,15341)$ & $(0,01493)$ & $(0,10057)$ & $(0,20878)$ & $(0,03627)$ & $(0,09254)$ & 0586) \\
\hline \multirow[b]{2}{*}{ q } & 4.481 .568 & 8.624 .371 & 5.426 .274 & 1.587 .171 & 10.983 .059 & .259 & 388.912 \\
\hline & (5.818.750) & $(4.203 .604)$ & (7.046.754) & (1.769.775) & $(5.78$ & $(1.710$ & (274.556) \\
\hline \multirow{2}{*}{ TA } & 37.854 .361 & 88.402 .368 & 41.412 .696 & 13.278 .689 & 92.380 .120 & 24.207 .906 & 3.026 .802 \\
\hline & (48.670.439) & (47.328.890) & $(53.037 .657)$ & (15.559.111) & (47.686.311) & (15.089.080) & $(2.233 .612)$ \\
\hline \multicolumn{8}{|c|}{ ETKINSIZZLiĞíN ETKILERi } \\
\hline \multirow{2}{*}{ d1 } & 0,91800 & 0,65589 & 0,92345 & 1,01323 & 0,78375 & 1,07744 & 0,93384 \\
\hline & & $(0,23938)$ & $(0,21803)$ & $(0,40928)$ & & $(0,13605)$ & $(0,41095)$ \\
\hline \multirow{2}{*}{ d2 } & 0,01823 & 0,01714 & 0,01793 & & & 0,01745 & 0,01679 \\
\hline & & & & & & & $(0,01352)$ \\
\hline \multirow{2}{*}{ d3 } & 0,07656 & 0,07837 & 0,07717 & 0,07505 & 0,07920 & 0,08497 & 0,06985 \\
\hline & $(0,03159)$ & $(0,03261)$ & $(0,03141)$ & $(0,03184)$ & $(0,02887)$ & $(0,03389)$ & $(0,03126)$ \\
\hline \multirow{2}{*}{ d4 } & 0,56054 & 0,46922 & 0,58358 & 0,56522 & 0,54044 & 0,64297 & 0,53038 \\
\hline & $(0,15252)$ & $(0,14443)$ & $(0,14410)$ & $(0,15551)$ & $(0,15028)$ & $(0,05834)$ & $(0,17386)$ \\
\hline \multirow{2}{*}{ d5 } & 0,48364 & 0,47271 & 0,48013 & 0,49266 & 0,42898 & 0,45665 & 0,54116 \\
\hline & & $(0,05639)$ & $(0,10311)$ & $(0,08843)$ & $(0,07673)$ & $(0,04555)$ & $(0,09063)$ \\
\hline \multirow{2}{*}{ d6 } & 1,96158 & 1,71574 & 1,76417 & 2,3287 & 1,68722 & 2,08765 & 2,10494 \\
\hline & $(0,75366)$ & $(0,24574)$ & $(0,28233)$ & $(1,10857)$ & $(0,27908)$ & $(0,34725)$ & $(1,05787)$ \\
\hline \multirow{3}{*}{ Gözlem } & $\mathrm{N}=189$ & $\mathrm{~N}=27$ & $\mathrm{~N}=93$ & $\mathrm{~N}=69$ & $\mathrm{~N}=63$ & $\mathrm{~N}=45$ & $\mathrm{~N}=81$ \\
\hline & $\mathrm{n}=21$ & $n=3$ & $\mathrm{n}=15$ & $\mathrm{n}=9$ & $n=7$ & $n=5$ & $n=9$ \\
\hline & $t=9$ & $t=9$ & $t=6,2$ & $t=7,7$ & $t=9$ & $t=9$ & $t=9$ \\
\hline
\end{tabular}

Not: (1) TA, toplam aktifleri ifade etmektedir.

(2) Değişkenlerin tanımlayıcı istatistik değerleri nominal değerler cinsinden verilmiştir. Standart hatalarının yüksek olduğu gözlemlenen bu değişkenler yöntem kapsamında normalize edilerek, ağırlıklandırılmış ve standart hatalar düşürülmüştür.

(3) Her bir değişken için ilk sıradaki değer ortalamasını, parantez içindeki değer standart sapmasını göstermektedir.

\subsection{Model}

Maliyet etkinliğinin hesaplanmasında parametrik yöntemlerden stokastik sınır analizinden yararlanılmıştır. Stokastik sınır yaklaşımı; Aigner, Lovell veSchmindt (1977), Meeusen veVan den Broeck (1977) ve Battese ve Corra (1977) tarafından birbirlerinden bağımsız şekilde öne sürülmüştür. Söz konusu üç çalışmada da sınır modelleri, üretim sınırı kapsamında bileşik hata yapısını içermektedir. Stokastik üretim fonksiyonunda etkinsizliğin olmaması durumunda ise üretim sınırında gerçekleşen ve etkin olan üretim düzeyi şu şekildedir:

$$
y_{i}^{*}=\exp \left(\beta_{0}+\beta_{1} \ln x_{i}+v_{i}\right)=\exp \left(\beta_{0}+\beta_{1} \ln x_{i}\right) \times \exp \left(v_{i}\right)
$$

Gerçekleşen üretimin, üretim sınırına oranı olan teknik etkinlik (technical efficiency - $T E_{i}$ ) aşağıdaki formülle hesaplanabilmektedir: (Coelli vd., 1998: 244) 


$$
T E_{i}=\frac{\exp \left(\beta_{0}+\beta_{1} \ln x_{i}+v_{i}-u_{i}\right)}{\exp \left(\beta_{0}+\beta_{1} \ln x_{i}+v_{i}\right)}=\exp \left(-u_{i}\right)
$$

Kumbhakar (1990), Cornwell vd. (1990) ve Battese ve Coelli (1992) tarafından geliştirilen stokastik sınır analizinde panel veri modelleri de analiz edilecek şekilde genişletilmiştir. Etkinsizliğin etkileri modeli ile de karar alma birimleri arasındaki teknik etkinsizliğin nedenleri belirlenmeye çalışılmaktadır. Diğer bir ifadeyle, teknik etkinsizliğin etkileri birinci aşamada ele alınırken, ikinci aşamada tahmin edilmiş etkinsizlik etkileri karar alma birimine özel faktörlerin fonksiyonu olarak ele alınmaktadır. Teknik etkinsizlik etkileri $u_{i t}$, açıklayıcı değişkenlerin $Z_{i t}$ ve bilinmeyen katsayılar vektörünün $\delta$, bir fonksiyonu olarak kabul edilmektedir Bu model aşağıdaki şekildedir:

$$
u_{i t}=Z_{i t} \delta+w_{i t}
$$

Buradaki $w_{i t}$, sıfır ortalama ve $\sigma^{2}$ varyans ile basık normal dağılıma sahip hata terimidir. $u_{i t}{ }^{\prime} \operatorname{ler}, Z_{i t} \delta$ ortalaması ve $\sigma^{2}$ varyans ile basık normal dağıımı varsayımı altında elde edilmektedirler.
Diğer taraftan, stokastik maliyet sınırı fonksiyonunun modellenmesi için varsayılan olgular sabit olmak üzere hata terimi $\left(v_{i}-u_{i}\right)$ 'den $\left(v_{i}+u_{i}\right)$ 'ye dönüştürülmelidir. Denklem (4) stokastik maliyet sınırının genel gösterimidir:

$$
\ln T C_{i t}=\ln T C\left(y_{i t}, p_{i t} ; \beta\right)+u_{i t}+v_{i t}
$$

Yazından bilindiği üzere, Cobb-Douglas, quadratic, normalize edilmiş quadratic, translog fourier esnek, genelleştirilmiş leontief, CES biçimindeki fonksiyonel kalıplar; maliyet etkinliği analizinde yaygın şekilde kullanılmaktadır. Karim vd. (2010) ve Almanidis (2013)'in çalışmalarında da belirtildiği üzere bankacılık sektörü özelinde maliyet etkinliğine hesaplanırken translog fonksiyonel kalıp en sık kullanılandır. Translog maliyet fonksiyonu, açıklayıcı değişkenler ve açıklanan değişkenler arasındaki etkileşimi yansıttığı; ayrıca kısıtlayıcı koşulları dikkate almaksızın daha esnek bir fonksiyonel yapıyı temsil ettiği için tercih edilmektedir. Genel bir ifadeyle, translog fonksiyon kalıbı şu şekildedir: (Christensen vd., 1973)

$$
y=\exp \left(\beta_{0}+\sum_{n=1}^{N} \beta_{n} \ln x_{n}+\frac{1}{2} \sum_{n=1}^{N-1} \sum_{m=1}^{N-1} \beta_{n m} \ln x_{n} \ln x_{m}\right)
$$

Parametrelerde doğrusallık varsayımı altında, her iki tarafın logaritmasını alarak translog fonksiyonu

kalıbında maliyet fonksiyonu aşağıdaki şekilde gösterilebilmektedir:

$$
\ln T C_{i t}=\ln T C\left(y_{i t}, w_{i t} ; \beta\right)
$$

Açık haliyle ise bu çalışmada kullanılan denklem şu şekildedir:

$$
\begin{aligned}
& \ln T C_{i t}=\beta_{0}+\sum_{j=1}^{2} \beta_{j} \ln \left(y_{j i t}\right)+\sum_{k=1}^{3} \alpha_{k} \ln \left(p_{k i t}\right)+ \\
& +\frac{1}{2} \sum_{j}^{2} \sum_{l}^{2} \delta_{j l} \ln \left(y_{j i t}\right) \ln \left(y_{l i t}\right)+\frac{1}{2} \sum_{k}^{3} \sum_{p}^{3} \varphi_{k p} \ln \left(p_{k i t}\right) \ln \left(p_{p i t}\right)+ \\
& +\frac{1}{2} \sum_{j}^{2} \sum_{k}^{3} \phi_{j k} \ln \left(y_{j i t}\right) \ln \left(p_{k i t}\right)+\psi_{1} \ln \left(q_{i t}\right)+\psi_{2} \operatorname{trend}++u_{i t}+v_{i t}
\end{aligned}
$$


$T C_{i t}$ : i bankasının t dönemindeki toplam maliyeti

$y_{j i t}$ : i bankasının t dönemindeki çıktılarını, $\mathrm{j}=1,2$

$p_{k i t}$ : i bankasının $\mathrm{t}$ dönemindeki girdi fiyatlarını, $k=1,2,3$

$q_{i t}$ : i bankasının t dönemindeki özkaynağı

$u_{i t}$ : Etkinsizlik bileşeni

$v_{i t}$ : Rassal bileşen

Özkaynaklar, bankalar arası gözlemlenen heterojenliği kontrol etmesi için modele dahil edilmiştir. Modelde simetri ve homojenlik kısıtları uygulanmıştır.

Simetri kısıtları:

$$
\begin{aligned}
& \delta_{j l}=\delta_{l j} \forall j, l \\
& \varphi_{k p}=\varphi_{p k} \forall k, p \\
& \phi_{j k}=\phi_{k j} \forall j, m
\end{aligned}
$$

Homojenlik kısıtları:

$$
\begin{aligned}
& \sum_{k}^{2} \alpha_{k}=1 \\
& \sum_{k} \sum_{k} \varphi_{k p}=\sum_{k} \phi_{j k}=0
\end{aligned}
$$

Homojenlik kısıtlarını modele dahil etmek için toplam maliyet ve diğer girdi fiyatları, bir girdi fiyatı ile bölünmelidir. Bu amaçla, toplam maliyet, emek fiyatı ve mevduat fiyatı; sermaye fiyatı ile bölünmüştür. Ayrıca Mitchell ve Onvural (1996) çalışması referans alınarak değişkenlerin logaritmaları alınmadan önce kendi ortalamalarına bölünerek ağırlıklandırma yapılmıştır. Böylece değişen varyans sorununu ortadan kaldırarak parametrelerin değerleri birbirine yaklaşmaktadır.

\subsection{Analitik Bulgular}

Burada öncelikle hipotez testine yönelik bulgu ve açıklamalara yer verilmektedir. Ardından modele yönelik bulgular ele alınmaktadır.

Tablo 4: Hipotez Testleri

\begin{tabular}{|c|c|c|c|c|c|}
\hline Boş Hipotez & Kritik Değer & Test İstatistikleri & Kabul / Red & Sonuç & $\operatorname{Pr}(>$ Chi sq) \\
\hline$H_{0}: \gamma=0$ & 5,138 & 44,428 & $H_{0}$ red & SFA & $6,948 \mathrm{e}-11^{*}$ \\
\hline$H_{0}: \mu=0$ & 2.706 & 1,779 & $H_{0}$ kabul & Yarı-normal & 0,1822 \\
\hline$H_{0}: \delta_{2}=\delta_{3}=\delta_{4}=0$ & 14.853 & 174,57 & $H_{0}$ red & $\begin{array}{c}\text { Etkinsizlik Etkileri } \\
\text { Modeli geçerli }\end{array}$ & $2,2 \mathrm{e}-16^{*}$ \\
\hline
\end{tabular}

Not: (1)*\%1 anlamlılık düzeyini ifade etmektedir.

(2) Kritik değerler; David A. Kodde ve Franz C. Palm, "Wald Criteria for Jointly Testing Equality and Inequality Restrictions", Econometrica, Cilt:54, 1986, ss.1243-1248 künyeli çalışmadan referans alınmıştır.

Tablo 4'te yer alan hipotez testine göre yarı normal dağılımlı, etkinsizlik etkilerinin olduğu translog maliyet fonksiyonunun tahmincileri yorumlanmıştır. Aracılık yaklaşımı çerçevesinde tarafımızdan belirlenen açıklayııı yapısal değişkenlerin (2 çıktı,
3 girdi fiyatı) yanı sıra etkinsizliğin kaynağı olarak dikkate aldığımız kontrol değişkenleri bir bütün olarak değerlendirilirken öncelikle modelin birinci aşaması ele alınmıştır. Tablo 5'te yer alan hata bileşenleri bulgularına yer verilmekle yetinilmiştir. 
Tablo 5: Hata Bileşenleri Model Tahmincileri

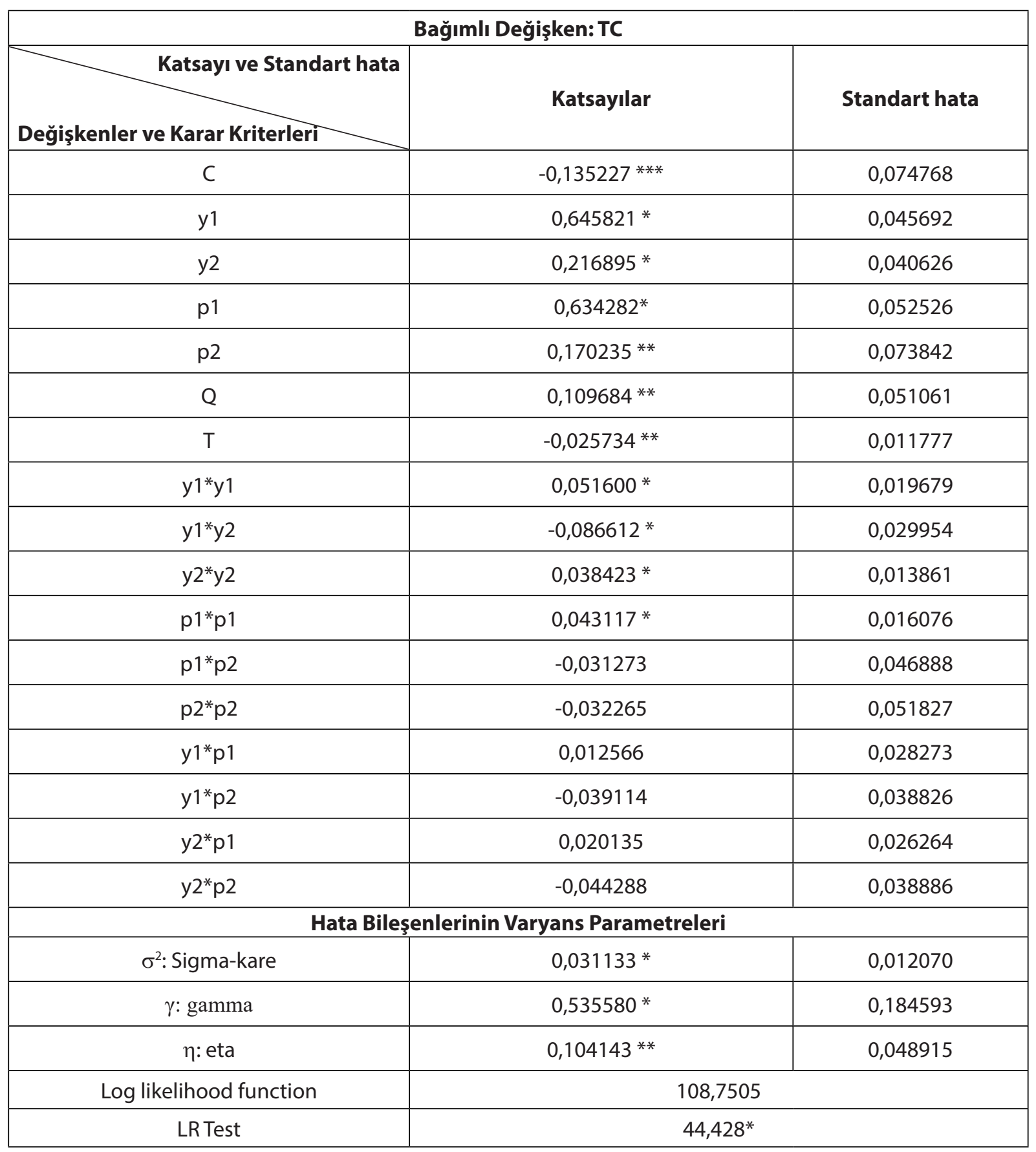

Not: $(1) * 0,01,{ }^{* *} 0,05,{ }^{* * *} 0,1$ düzeyinde anlamlılığı ifade etmektedir.

(2) Bağımlı değişken ve girdi fiyatları "Amortisman giderleri / Maddi duran varlıklar" olan sermaye fiyatı ile normalize edilmiştir.

Buna göre, model tanımlaması tüm göstergeler itibariyle anlamlı olup değişkenlerin katsayıları yorumlanabilir bulunmuştur. Bu aşamayı takip eden maliyet etkinsizliğinin teknik etkileri modelinin sınanabileceği öngörülmüş ve öncelikle maliyet etkinsizliğine yol açabileceğini düşündüğümüz veri tabanında belirtilen finansal rasyolara ilişkin değişkenler, Sperman sıra korelasyonu ile test edilmiştir. Ardından teknik etkinsizliğin temel kaynağı olabileceği öngörüsüyle Akaike (AIC) bilgi kriterine göre belirlenen etkinsizlik etkileri değişkenleri teknik etkinsizliğin etkileri modeline dahil edilmiş ve maliyet etkinsizliğine yol açan ikinci aşama modelin sonuçları Tablo 6'de yer alan şekliyle aşağıda rapor edilmiştir. 
Tablo 6: Teknik Etkinsizliğin Etkileri Modeli

\begin{tabular}{|c|c|c|}
\hline \multicolumn{3}{|c|}{ Bağımlı Değişken: TC } \\
\hline Değişkenler ve Karar Kriterleri & Katsayılar & Standart hata \\
\hline $\mathrm{C}$ & $-0,1928871^{*}$ & 0,0384408 \\
\hline $\mathrm{y} 1$ & $0,7925783^{*}$ & 0,0421401 \\
\hline $\mathrm{y} 2$ & $0,0696550^{*}$ & 0,0270377 \\
\hline p1 & $0,6927089^{*}$ & 0,0358 \\
\hline p2 & $0,1210107^{* *}$ & 0,0465939 \\
\hline $\mathrm{Q}$ & $0,1224137^{*}$ & 0,0352104 \\
\hline $\mathrm{T}$ & $-0,0322928^{*}$ & 0,0050202 \\
\hline $\mathrm{y} 1 * \mathrm{y} 1$ & $0,0250672^{* * *}$ & 0,0178092 \\
\hline $\mathrm{y} 1 * \mathrm{y} 2$ & $-0,0307066$ & 0,0273442 \\
\hline $\mathrm{y} 2 * \mathrm{y} 2$ & $0,0086642^{* * *}$ & 0,0118671 \\
\hline $\mathrm{p} 1 * \mathrm{p} 1$ & $0,0292607^{*}$ & 0,0171740 \\
\hline $\mathrm{p} 1 * \mathrm{p} 2$ & 0,0220069 & 0,0406664 \\
\hline p2*p2 & $-0,0514263$ & 0,0404072 \\
\hline $\mathrm{y} 1 * \mathrm{p} 1$ & $-0,0016155^{* * *}$ & 0,0260610 \\
\hline$y 1 * p 2$ & $-0,0458848$ & 0,0329426 \\
\hline$y 2 * p 1$ & 0,0294779 & 0,0242273 \\
\hline $\mathrm{y} 2 * \mathrm{p} 2$ & $-0,0510381$ & 0,0338220 \\
\hline \multicolumn{3}{|l|}{ Etkinsizlik Kaynağı Olarak Öngörülen Değ. } \\
\hline$d_{0}$ & $0,9169641^{*}$ & 0,1350662 \\
\hline$d_{1}$ & $-0,1240973^{* *}$ & 0,0603307 \\
\hline$d_{2}$ & $4,9825207^{*}$ & 0,7132279 \\
\hline$d_{3}$ & $0,8843410^{* *}$ & 0,4202191 \\
\hline$d_{4}$ & $-1,2278994 *$ & 0,1841323 \\
\hline$d_{5}$ & $-0,3616284 * *$ & 0,1767161 \\
\hline$d_{6}$ & $0,0655433^{* *}$ & 0,0272307 \\
\hline \multicolumn{3}{|l|}{ Hata Bileşenlerinin Varyans Parametreleri } \\
\hline$\sigma^{2}:$ Sigma-kare & $0,0117542^{*}$ & 0,0020258 \\
\hline$\gamma:$ gamma & $0,7034708^{*}$ & 0,1294646 \\
\hline Log likelihood function & \multicolumn{2}{|c|}{173,8224} \\
\hline LR Test & \multicolumn{2}{|c|}{174,57} \\
\hline
\end{tabular}

Not: $(1) * 0,01,{ }^{* *} 0,05,{ }^{* * *} 0,1$ düzeyinde anlamlılığı ifade etmektedir.

(2) Bağımlı değişken ve girdi fiyatları "Amortisman giderleri / Maddi duran varlıklar" olan sermaye fiyatı ile normalize edilmiştir.

Buna göre, seçilen modelin hipotez testleri dikkate alındığında görülmektedir ki stokastik sınır analizi (SFA) ekonometrik ve istatistiki göstergeleri bir bütün olarak anlamlıdır. Hata bileşenlerinin varyansının çoğunlukla etkinsizliğin kaynağı olan bileşenlerden doğduğu saptanmıştır. Nitekim gama parametresi 0,7034 olup çıktıdaki varyansın \%70,34'i tarafımızdan belirlenmiş yapısal değişkenlerin varyansındaki değişmeyle açılanırken geriye kalan \%29,66'sı kontrolümüz dışında olan içsel veya dışsal değişkenlerin etkisi olarak bilinen rassal hata ile açıklanabilir.

Etkinsizliğin etkilerine ilişkin değişkenlerin katsayılarının işareti beklentilerimizle uyumludur. $\mathrm{Bu}$ değişkenlerden, mevduatın krediye dönüşüm oranını, aktifler içindeki krediler ve alacakların payı ve personel gider oranı arttıkça maliyet etkinliği artmakta; kredi kayıp karşılığı oranı, likidite oranı ve faiz karşılama oranı arttıkça ise maliyet etkinliği azalmaktadır. 
Bu kapsamda, maliyet etkinliği değerleri yorumlanabilmektedir. Illk olarak mevduat bankaları için ağırlıklandırılmış maliyet etkinliği değerleri aşağıdaki şekilde gösterilmektedir:

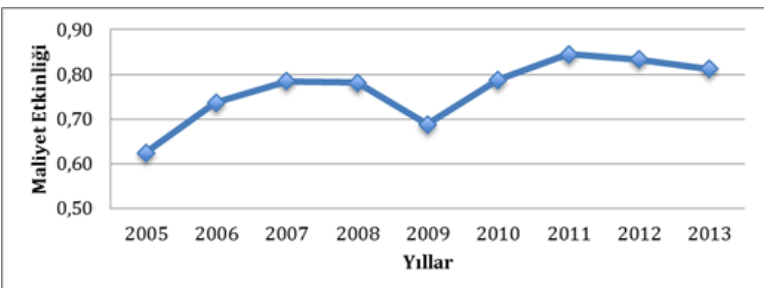

Şekil 1: Mevduat Bankalarının Ağırlıklandırılmış Maliyet Etkinliği

2005 - 2013 döneminde faaliyet gösteren 21 mevduat bankasına ait ağırlıklı ortalama maliyet etkinliği \%76,605'dir. Yani bu çalışmada ele alınan 21 mevduat bankası söz konusu dönemde, aynı koşullarda faaliyet gösteren ve aynı çıktıyı üreten en etkin bankaya kıyasla ortalama olarak \%76,605 etkindir. Diğer bir ifadeyle, ortalama olarak mevduat bankaları \%23,395 oranında maliyet etkinsizdir, aynı koşullarda faaliyet gösteren ve aynı çıktıyı üreten en etkin bankaya kıyasla maliyetlerini \%23,395 oranında düşürebilmekte yani daha fazla maliyete katlanmaktadır.

Maliyet etkinliğinde en düşük seviye olan \%62,483 ortalama değeri 2005 yılında görülürken, en yüksek seviye olan \%84,558 ortalama değeri 2011 yılında görülmüştür. 2008 küresel bunalımın etkisi önemli ölçüde hissedilmiş, 2009 yılından sonra toparlanma görülmüştür. 2012 yılında da ekonomide yaşanan sorunlar maliyet etkinliğinde düşüş olarak kendini göstermiştir.

Çalışmada ele alınan 21 mevduat bankasından en etkin ilk üç banka Tablo 7'de görüldüğü üzere Akbank T.A.Ş., Fibabanka A.Ş. ve Turkland Bank A.Ş. iken, en az etkin üç banka ise Turkish Bank A.Ş., Citibank A.Ş. ve Türkiye Cumhuriyeti Ziraat Bankası A.Ş.'dir.

Tablo 7: Bankaların Maliyet Etkinliği Ortalamaları (2005-2013)

\begin{tabular}{|l|c|l|c|}
\hline Banka Adı & $\begin{array}{c}\text { Maliyet } \\
\text { Etkinliği }\end{array}$ & Banka Adı & $\begin{array}{c}\text { Maliyet } \\
\text { Etkinliği }\end{array}$ \\
\hline Akbank T.A.Ş. & 0,97317 & Türk Ekonomi Bankası A.Ş. & 0,84509 \\
\hline Fibabanka A.Ş. & 0,97053 & Denizbank A.Ş. & 0,83817 \\
\hline Turkland Bank A.Ş. & 0,96907 & Türkiye Halk Bankası A.Ş. & 0,82414 \\
\hline ING Bank A.Ş. & 0,94411 & HSBC Bank A.Ş. & 0,82162 \\
\hline Alternatifbank A.Ş. & 0,93975 & Burgan Bank A.Ş. & 0,79495 \\
\hline Arap Türk Bankası A.Ş. & 0,93959 & Yapı ve Kredi Bankası A.Ş. & 0,76384 \\
\hline Anadolubank A.Ş. & 0,93120 & Türkiye İş Bankası A.Ş. & 0,74780 \\
\hline Türkiye Garanti Bankası A.Ş. & 0,90138 & Türkiye Cumhuriyeti Ziraat Bankası A.Ş. & 0,72230 \\
\hline Türkiye Vakıflar Bankası T.A.O. & 0,87411 & Citibank A.Ş. & 0,69950 \\
\hline Tekstil Bankası A.Ş. & 0,86798 & Turkish Bank A.Ş. & 0,68097 \\
\hline Finans Bank A.Ş. & 0,85834 & & \\
\hline
\end{tabular}

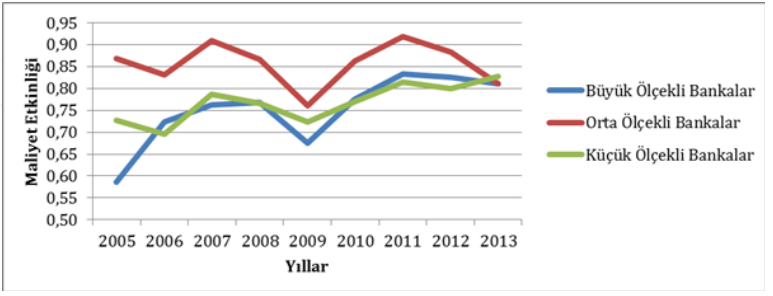

Şekil 2: Ölçek Yapılarına Göre Bankaların Maliyet Etkinliği
Orta ölçekli bankalarda, maliyet etkinliği \%85,7 ile en yüksek düzeyde gözlemlenmektedir. Ardından sırasıyla küçük $(\% 76,8)$ ve büyük $(\% 75,1)$ ölçekli bankalar maliyet etkindir. Işık ve Hassan (2002) çalışmasıyla paralel sonuçlar bulunmuştur. Büyük ölçekli bankaların piyasa payı yüksek olduğu için örneklemdeki tüm mevduat bankalarıyla büyük ölçekli bankaların maliyet etkinliği trendi aynıdır. 
Sermaye yapılarına göre bankaların maliyet etkinlik değerleri ise Şekil 3'te gösterilmektedir.

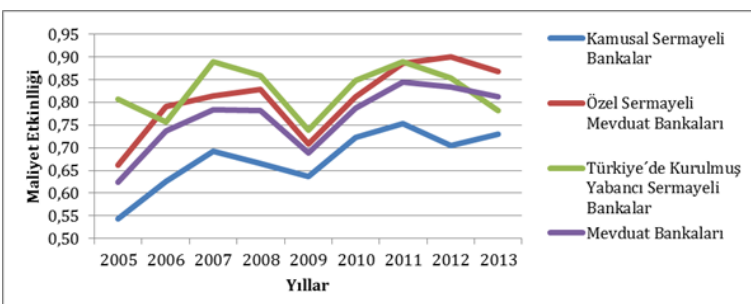

Şekil 3: Sermaye Yapılarına Göre Bankaların Maliyet Etkinliği

Yabancı sermayeli bankalar, \%82,5 ile en yüksek maliyet etkinlik değerine sahipken, özel sermayeli bankalar \%80,8 ve kamusal sermayeli bankalar ise \%67,5 maliyet etkinlik değerine sahiptir.Zaim (1995) ve Işık ve Hassan (2002) çalışmalarında benzer sonuçlara ulaşmışlardır. Kamusal sermayeli bankaların maliyet etkin faaliyet göstermemelerinin nedenlerinden biri, maliyet minimizasyonu dışında hükümet politikalarını sürdürmeye çalışmaları da olabilmektedir. Özel sermayeli bankalar örneklemimizdeki bankaların büyük bir payını oluşturduğu için mevduat bankalarının trendi özel sermayeli bankaların trendi ile benzerlik göstermektedir.

\section{SONUÇ}

Bu çalışmada 2005 - 2013 yılları arasında Türkiye bankacılık sisteminin ise \%93,3'ünü kapsayan 21 mevduat bankasının maliyet etkinliği, parametrik yöntemlerden stokastik sınır analizi (SFA) yardımıyla hesaplanmıştır.

Buna göre, 2005 - 2013 döneminde faaliyet gösteren 21 mevduat bankasına ait ağırlıklı ortalama maliyet etkinliği \%76,605'dir. Maliyet etkinliğinde en düşük seviye olan \%62,483 ortalama değeri 2005 yılında görülürken, en yüksek seviye olan \%84,558 ortalama değeri 2011 yılında görülmüştür. 2008 küresel bunalımın etkisi önemli ölçüde hissedilmiş, 2009 yılından sonra toparlanma görülmüştür. 2012 yılında da ekonomide yaşanan sorunlar maliyet etkinliğinde düşüşe neden olmuştur.

Maliyet etkinliği değerleri; ölçek ve sermaye yapıları bazında alt gruplar şeklinde de analiz edilmiştir. Maliyet etkinliği \%85,7 ile en yüksek orta ölçekli bankalarda gözlemlenmektedir. Ardından sırasıyla küçük $(\% 76,8)$ ve büyük $(\% 75,1)$ ölçekli bankalar maliyet etkindir. Sermaye yapısı bakımından incelendiğinde; yabancı sermayeli bankaların, \%82,5 ile en yüksek, ardından özel sermayeli bankaların $\% 80,8$ ve kamusal sermayeli bankaların ise \%67,5 oranında maliyet etkinlik değerine sahip olduğu gözlemlenmiştir. Etkinsizliğin etkilerini açıklayan parametrelerin katsayıları yorumlandığında sırasıyla aşağıdaki sonuçlar çıkarılmıştır.

- Mevduatın krediye dönüşüm oranını ifade eden "Krediler ve Alacaklar / Mevduat" oranı arttıkça etkinsizliğin etkileri azalmakta, yani maliyet etkinliği artmaktadır. Burada katsayının işaretinin negatif olması beklentilerle uyumlu olup bu sonuç, bankacılık sektöründe yönetim etkinliğinin (x-etkinliğine karşılık gelen teknik etkinlik göstergesi) kısmen daha da iyileşebileceği şeklide yorumlanabilir.

- "Toplam Krediler ve Alacaklar / Toplam Aktifler" oranı arttıkça etkinsizliğin etkileri azalmakta yani maliyet etkinliği artmaktadır. Bu değişken, mevduatın krediye dönüşüm oranı olarak kullanılan "Krediler ve Alacaklar/ Mevduat" oranının sonuçlarını destekleyen bir gösterge olarak değerlendirilmiştir.

- "Kredi kayıp karşılığı" olarak kabul gören "Kredi ve Diğer Alacaklar Değer Düşüş Karşılığı / Krediler ve Alacaklar" oranı arttıkça etkinsizliğin etkileri artmakta yani maliyet etkinliği azalmaktadır. Ulaşılan katsayının işareti de beklentiyle uyumludur. Bu açıdan değerlendirildiğinde, bankalar vermiş oldukları kredilerden yeniden yapılandırma yoluyla elde edecekleri gelirden feragat etmelerine rağmen, şüpheli alacak haline gelmiş bir geliri likidite etmiş olmaktadırlar. Böylece söz konusu işlemle bu bankaların likidite sağlamayı öngörebildiklerini söylemek mümkündür.

- Likidite oranı göstergelerinden biri olarak kabul edilen "Nakit Değerler ve Merkez Bankası / Toplam Aktifler" oranı arttıkça etkinsizliğin etkileri artmaktadır.Böylecemaliyet etkinliğiazalmaktadır. Elde edilen tahmin sonucuna göre, parametreye karşılık gelen katsayının işareti beklentilerle uyumludur. Bu sonuca göre, para politikasında miktara dayalı uygulamaların bankaların maliyetlerini arttıracağı ifade edilebilmektedir. Diğer bir ifadeyle, merkez bankasının karşılık oranlarını arttırması sonucunda bankaların kasalarında bulundurdukları likiditenin maliyeti artacaktır. Bu açıdan ele alınan dönemde, parasal aktarma mekanizmalarının iki kanalı olan banka 
bilançosu ve kredi kanalıyla bankalar aleyhine bir sonuç doğduğu ve merkez bankasının para politikası aracı olarak kullandığı zorunlu karşılıkların yönetimi açısından da etkin bir araca başvurulduğunu söylemek mümkündür. Bunun sonucunda kredi maliyetleri artarsa, bu durum reel ekonomi açısından kaynak tahsisini bozan temel bir olguya işaret etmektedir.

- Personel gider oranı olarak değerlendirdiğimiz "Personel Giderleri / Diğer Faaliyet Giderleri" oranı arttıkça etkinsizliğin etkileri azalmakta yani maliyet etkinliği artmaktadır. Bu sonuç finansal sektörde emek - sermaye ilişkisindeki ikame faktörünün değerlendirilmesi bağlamıyla emeğin kalitesindeki artışın (bilgi ekonomisinin sağladığı dışsallıklar ve yaygın uzmanlaşma ile birlikte alan ekonomisinin) sermayenin kullanım etkinliğini arttırdığı anlamına gelmektedir. Dolayısıyla bu sonuç da yönetim etkinliğinin bir başarı göstergesi olarak değerlendirilebilir.

- Faiz karşılama oranı olarak bilinen "Faiz Gelirleri / Faiz Giderleri" oranı arttıkça etkinsizliğin etkileri artmakta yani maliyet etkinliği azalmaktadır. Bu gösterge de temelde likidite oranının sonuçlarını desteklemekte olup bankanın kullandırmış olduğu kaynağından elde etmiş olduğu faiz gelirlerinin aynı zamanda maliyet arttırıc bir etki yarattığını göstermektedir. Böyle bir bulgunun ana nedeni, faiz gelirlerinin artmasına yol açacak faktörlere bağlanabilmektedir. Bu kaynağın vergi kalkanı benzeri bir finansman aracını kullanma eğilimine bağlı olduğu düşünülmektedir. Özellikle yurtdışından kullanılan kaynakların risk primine bağlı maliyeti dikkate alındığında faiz gelirlerinin bu risk primine bağlı olarak arttırılması bir zorunluluktur. Faiz gelirindeki artışın maliyet etkinsizliğine yol açan bir etken olarak görülmesinin örtük olarak kullanılan kaynağın temelindeki risk faktörüyle maliyet arttırıcı etkilerden kaynaklandığı ifade edilebilmektedir.

Özetle, yukarıdaki sonuçlar bir bütün olarak değerlendirildiğinde analiz döneminde kredi maliyetlerinde ortaya çıkan belirgin artışların, hem finans sistemi hem de reel ekonomi üzerinde kaynak tahsisini bozucu etki yarattığı belirlenmiştir.

SON NOTLAR: Bu çalışma, Dokuz Eylül Üniversitesi Sosyal Bilimler Enstitüsü Iktisat Ana Bilim Dalı'nda hazırlanan, 'Finansal ve Reel Sektörler Arası Etkileşime Dayalı Tahsis Etkinliği: Türkiye Örneği, 2005-2013' başlıklı doktora tezinden türetilmiştir.

\section{KAYNAKÇA}

Aigner, D., Lovell, K. ve Schmidt, P. (1977) “Formulation and Estimation of Stochastic Frontier Production Functions", Journal of Econometrics, 6: 21-37.

Almanidis, P. (2013) "Accounting for heterogeneous technologies in the banking industry: a time-varying stochastic frontier model with threshold effects", Journal of Productivity Analysis, 39 (2): 191-205.

Bankacılık Düzenleme ve Denetleme Kurumu, "Bankacılıkta Yapısal Gelişmeler: 2006-2011", http:// www.bddk.org.tr/WebSitesi/turkce/Raporlar/ Bankacilikta Yapisal Gelismeler/Bankacilikta

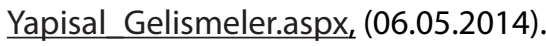

Battese, G. E. ve Corra, G. S. (1977) "Estimation of a Production Frontier Model: With Asslication to the Pastoral Zone off Eastern Australia", Australian Journal of Agricultural Economics, 21: 169-179.

Berger, A. N. ve Humphrey, D. B. (1992) Measurement and Efficiency Issues in Commercial Banking, Output Measurement in the Service Sector, (Ed. Zvi Griliches), The University of Chicago Press, Chicago, 245-300.
Berger, A. N. ve Humphrey, D. B. (1997) “Efficiency of Financial Institutions: International Survey and Directions for Future Research", European Journal of Operational Research, 98(2): 175-212.

Christensen, L. R., Jorgenson D. W. ve Lau, L. J. (1973) "Transcendental Logarithmic Production Frontiers", Review of Economics and Statistics, 55(1): 25-45.

Coelli, T., Rao, P. O’Donnell, C. J. ve Battese, G. E. (1998) An Introduction to Efficiency and Productivity Analysis, Springer, USA.

Cornwell, C., Schmidt, P. ve Sickles, R. C. (1990) "Production Frontiers with Cross-sectional and Time-series Variation in Efficiency Levels", Journal of Econometrics, 46(1-2): 185-200.

Dikmen, F. H. (2013) "Türk Bankacılık Sektörü İçin Bir Etkinlik Analizi: 2003-2007", Ekonomik Yaklaşım, 23(85): 83-120.

El-Gamal, M. ve İnanogłu, H. (2005) "Inefficiency and Heterogeneity in Turkish Banking: 1990-2000", Journal of Asslied Econometrics, 20: 641-664. 
George E. Battese ve Timothy J. Coelli, (1992) "Frontier Production Functions, Technical Efficiency and Panel Data: With Application to Paddy Farmers in India", Journal of Productivity Analysis, 3: 153-169.

Günalp, B. ve Celik, T. (2004) “Türk Bankacilık Sisteminde Piyasa Yapısı ve Performans Ilisskilerinin Etkinlik Için Dogrudan Bir Ölçuit Kullanılarak Test Edilmesi", Gazi Universitesi I.I.B.F. Dergisi, 6(3): 31-57.

Hancock, D. (1985) "The Financial Firm: Production with Monetary and Nonmonetary Goods", Journal of Political Economy, 93(5): 859-880.

Işık, I. ve Hassan, M. K. (2002) "Cost and Profit Efficiency of the Turkish Banking Industry: An Emprical Investigation", The Financial Review, 37: 257-280.

Kasman, A. (2002) "Cost Efficiency, Scale Economies and Technological Progress in Turkish Banking", Central Bank Review, 2(1):1-20.

Karim, M., Chan, S. ve Hassan, S. (2010)"Bank Efficiency and Non-Performing Loans: Evidence from Malaysia and SingaporePrague Economic Papers", 2: 118-132.

Kumbhakar, S. C. (1990) "Production Frontiers, Panel Data and Time-Varying Technical Efficiency", Journal of Econometrics, 46: 201-212.

Kumbhakar, S. C. ve Knox Lovell, C. A. (2003) Stochastic Frontier Analysis, Cambridge University Press, USA.

Meeusen, W. ve Van Den Broeck, J. (1977) “Efficiency Estimation from Cobb-Douglas Production Functions with Composed Error", International Economic Review, 18(2): 435-444.

Mitchell, K. ve Onvural, N. M. (1996) "Economies of Scale and Scope at Large Commercial Banks: Evidence from the Fourier Flexible Functional Form", Journal of Money, Credit and Banking, 28(2): 178-199.

Resti, A. (1997) "Evaluating the Cost Efficiency of the Italian Banking System: What can be Learned from the Join Application of Parametric and Non-parametric Techniques", Journal of Banking and Finance, 21(2): 221-225.

Sealey, C. W. ve Lindley, J. (1977) "Inputs, Outputs and a Theory of Production and Cost at Depository Financial Institutions", Journal of Finance, 32(4): 12511266.

Türkiye Bankalar Birliği, "31.12.2013 Tarihi İtibariyle Üye Bankaların Bilgileri", http://www. tbb.org.tr/modules/banka-bilgileri/banka Listesi. asp?tarih=31/12/2013, (06.05.2014).

Türkiye Bankalar Birliği, Veri Sorgulama Sistemi, Mali Tablolar, http://www.tbb.org.tr/tr/banka-ve-sektorbilgileri/veri-sorgulama-sistemi/mali-tablolar/71, (06.05.2014).

Türkiye Bankalar Birliği, Bankalarımız 2013, Yayın No:304, İstanbul, 2014.

Wang D. ve Kumbhakar, S. C. (2009) "Strategic Groups and Heterogeneous Technologies: An Application to the US Banking Industry", Macroeconomics and Finance in Emerging Market Economies, 2(1): 31-57. 